\title{
WORKING
}

paper

\section{Firm-level Productivity Dispersion and Convergence}

\section{Gilbert Cette ${ }^{1}$, Simon $\operatorname{Corde}^{2} \&$ Rémy Lecat $^{3}$}

\author{
February 2018, WP \#662
}

\begin{abstract}
The productivity slowdown has been analysed as an effect of weaker technological progress, of the digital economy or of a less efficient reallocation process. Using data on firms operating in France, we highlight that, at the technological frontier, productivity has accelerated, especially over the recent period, which contradicts the hypothesis of a decline in innovation. The most productive firms in a given year do not, however, improve their relative advantage. The convergence of firms' productivity does not seem to have slowed down in the 2000s, which does not confirm the hypothesis of a decrease in the dissemination of innovation. On the other hand, the dispersion of productivity between firms has increased, which suggests growing difficulties in reallocating production factors, labour and capital, between firms.
\end{abstract}

Keywords: total factor productivity, dissemination of innovation

JEL classification: E22, L11, O47

\footnotetext{
${ }^{1}$ Banque de France et Université Aix-Marseille, Aix-Marseille School of Economics, gilbert.cette@,banquefrance.fr;

${ }^{2}$ Banque de France, simon.corde@ensae-paristech.fr;

${ }^{3}$ Banque de France, remy.lecat@,banque-france.fr.

We thank seminar participants at the OECD and at the conference "Productivité : une énigme française ? " and to our discussant Giuseppe Nicoletti for their comments, Roxanne Tabouret for her research assistance, Sébastien Roux for his methodological advise. All errors remain ours.
}

Working Papers reflect the opinions of the authors and do not necessarily express the views of the Banque de France. This document is available on publications.banque-france.fr/en 


\section{Introduction}

At the beginning of the 2000s, that is before the financial crisis, productivity has seen a slowdown in all the main developed countries, including France (on this topic see Bergeaud et al., 2016 and on France, Cette et al., 2017). Several explanations have been put forward:

- A decline in the contribution of technological progress to productivity growth (Gordon, 2012). In this hypothesis, productivity should then slow down for companies at the frontier.

- A decline in the dissemination of technologies between companies at the frontier and those not, due to the growing importance of "tacit knowledge" (Andrews et al., 2015). The convergence of the productivity levels of the least to the most productive companies should then decelerate.

"Winner takes all" phenomena linked to the characteristics of information and communication technologies (ICT). In this case, the most productive companies' productivity should rapidly accelerate relative to the least productive companies.

- An insufficiently efficient reallocation when faced with crises that require significant sectoral and geographical reallocation of the production factors, which would lead to growing productivity dispersion among firms (Bartelsman et al., 2013).

The aim of this article is, within the well-outlined framework of the French economy, to investigate these explanations.

\section{Data}

Our dataset is composed of firms operating in France. The total factor productivity (TFP) indicator is output volume $(\mathrm{Q})$ over a geometric average (in accordance with a Cobb-Douglas function) of the two factors considered, capital $(\mathrm{K})$ and labour $(\mathrm{L})$. We expect constant returns from two factors of production: TFP $=\mathrm{Q} /\left(\mathrm{K}^{\alpha} \cdot \mathrm{L}^{1-\alpha}\right)$, with $\alpha$ set according to the average value of the share of revenue for each sector. The mobilised individual company data are taken from Fiben, which gathers accounting data (corresponding to the tax returns) of all companies whose turnover exceeds $€ 750,000$ per year or which hold more than $€ 380,000$ in credit, leading to an unbalanced sample made up of between 59,767 and 130,750 companies per year over the 1992-2014 study period.

\section{Productivity at the frontier and dispersion}

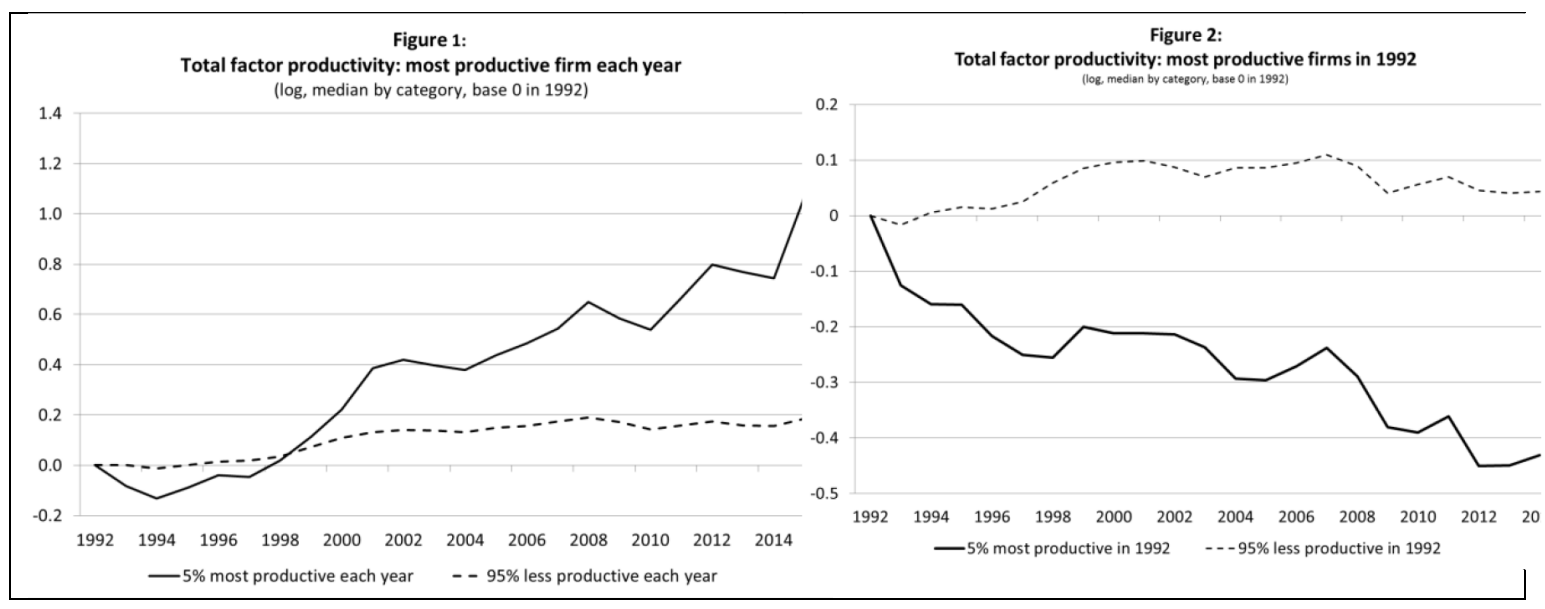

We will examine the evolution of the productivity of companies at the frontier from two angles. 
Firstly, fig. 1 represents the median productivity of the $5 \%$ most productive companies of the year ${ }^{3}$. The black line therefore defines the productivity frontier, with a renewal each year of the companies that define it. The dotted line corresponds to the median productivity of the other $95 \%$ companies. These results are very closely in line with the results of Andrews et al. (2015) over international data, which interpret the opening gap between the frontier and the laggard firms as resulting from a decline of the technology diffusion process. The financial crisis did not slow down these trends. The concept of the productivity frontier is nevertheless problematic: in fact, we notice that the companies in our database stay on average for 3 years among the most productive in a given year. The frontier represented in fig. 1 therefore corresponds to a temporary performance, possibly unsustainable in the long term for a large proportion of firms.

Secondly, with fig. 2 , the median productivity of the most productive companies in $1992^{4}$ follows a downward trend, whereas it increases for the least productive companies at this same date. The difference with fig. 1 is that there is no entry of new firms in the sample, for the most as well as the least productive firms, the black line being constituted from the most productive companies in 1992, but not necessarily the years after, which remain in the database. This figure indicates a convergence of the companies' productivity over the whole period: the most productive companies' productivity at a given date decreases compared to that of the other companies. It should nevertheless be noted that the median productivity of the most productive companies in 1992 remains twice higher than the one of the least productive companies by the end of the period.

These trends do not support the idea of a decline in technological progress, the hypothesis defended by Gordon: whatever is the frontier definition, it does not decelerate. They do not seem either in line with a 'winner-takes-all' dynamic: the productivity of the most productive companies does not accelerate, contrary to what would be expected if these companies gained more and more market share at zero marginal cost. It does indeed seem difficult to envisage that a dynamic of this type could apply to all sectors of the economy, and not mainly in the ICT and digital sectors (economy of scale linked to network effects, non-rival goods).

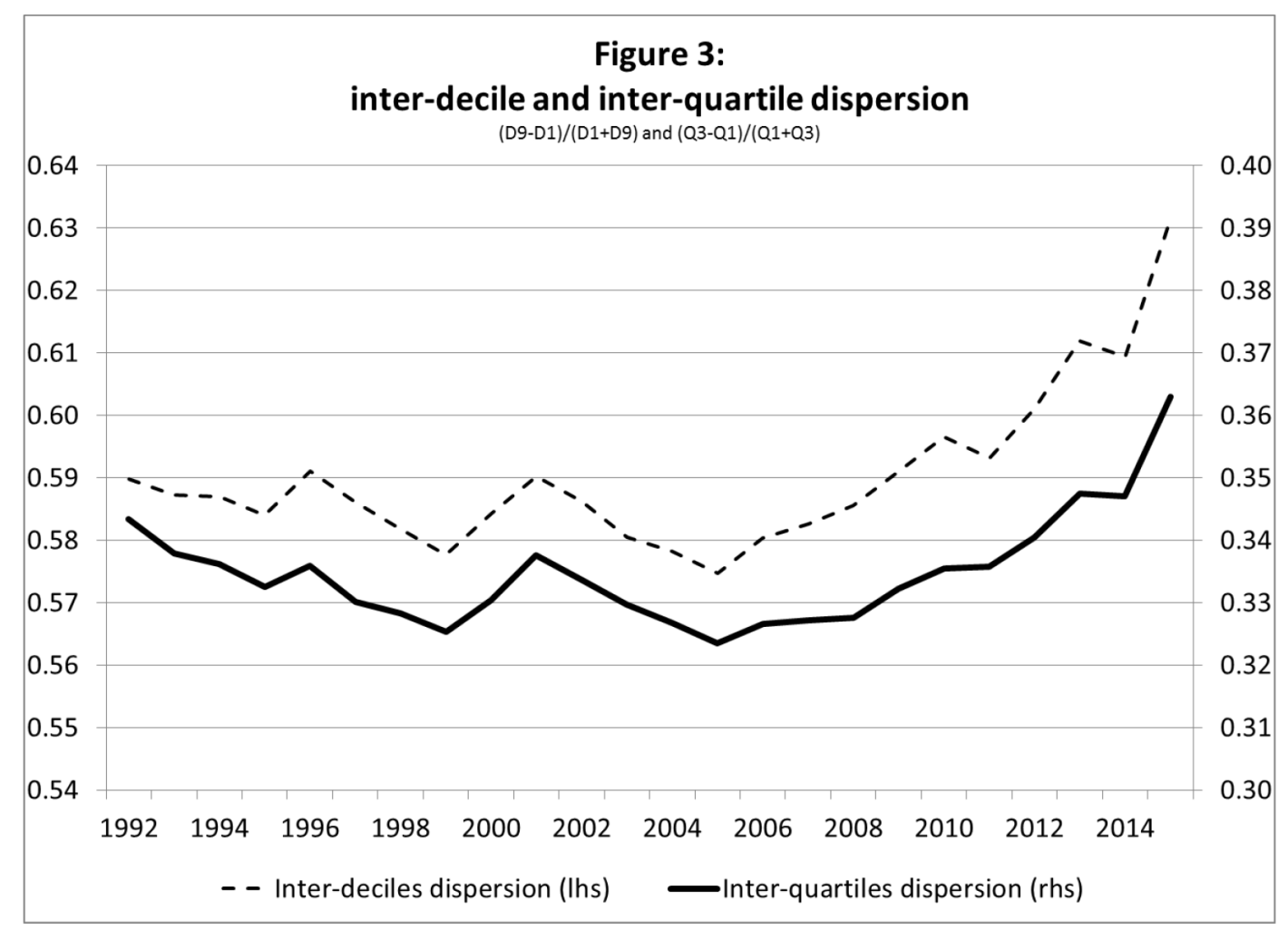

\footnotetext{
${ }^{3}$ These results and the followings are qualitatively robust to the use of the $2 \%$ or $10 \%$ best performers.

${ }^{4}$ The trends are qualitatively similar with 1995,2000 or 2005 as a benchmark.
} 
Fig. 3 represents the interquartile or interdecile firm productivity levels dispersion. The dispersion has greatly increased since the crisis and reaches its highest levels at the end of the period. This may correspond to the hypothesis of reallocation difficulties following shocks. In fact, sectoral shocks can emphasise the need to reallocate, but if market rigidities or a lack of skilled labour stifle these reallocations, low-productive companies will continue to operate and their productivity will slow down, whereas that of successful companies with adequate factors of production accelerates. This may also correspond to a longer survival of low-productivity firms, which may be related to the trend decrease in real interest rates since the end-1980s and consequently a deterioration of the 'cleansing mechanism'.

\section{Productivity convergence}

Among the hypotheses to explain the slowdown in productivity at the aggregate scale, Andrews et al. (2015) have highlighted a slower convergence of the least productive companies' productivity with that of the most productive ones. This slower convergence could be explained by low dissemination of technological progress from the most productive companies to the least productive.

To study the evolution of the speed of convergence over the period, we estimate the following relation:

$\Delta t p p_{i t}=a .\left(t p p(95 \%)_{t-1}-t p_{i t-1}\right)+\sum_{j=1991}^{2014} \beta_{j} . D_{j} \cdot\left(t p p(95 \%)_{j-1}-t p_{i j-1}\right)+D_{t}+D_{s}+D_{a}+\varepsilon_{i t}$

with the indices $i$ for the company, $s$ for the sector and $t$ for the year, thp is the log of TFP, $t p(95 \%)$ the $\log$ of the median TFP of the 5\% most productive companies in their sector, $D_{j}$ year dummies; $D_{b}, D_{s}$ et $D_{a}$, are fixed effects for year, sector and size, and $\varepsilon_{i s t}$ the error term.

The speed of convergence in year $j$ is then $\alpha+\beta_{j}$, which are presented in fig. 4 . There is convergence if the sum of the two coefficients is significant and positive.

It appears that the speed of convergence slowed down throughout the 1990s, with a low point in 1999. It then stagnated until the financial crisis. The shock of the financial crisis led to an acceleration of the convergence largely due to the economic climate and adjusted accordingly after. In 2014, the convergence slows down considerably. Other years must nevertheless be observed in order to confirm this new stalling of the speed of convergence, observed over one sole year at this stage.

While there was a visible slowdown in the speed of convergence in the 1990s (confirming the results of Chevalier et al., 2012), the slowdown since the 2000s or 2010 has not been proven.

This result contrasts with that of an increase of dispersion measured by indicators of the interdecile or interquartile range (see fig. 3). These two approaches are not independent of each other but differ in several ways: i) the $\beta$-convergence is estimated by taking into account an error term $\varepsilon_{i s t}$, whereas the dispersion indicators integrate the temporary shocks; ii) the $\beta$-convergence is estimated over companies present for two consecutive years, whereas the dispersion is characterised over all the companies present each year; iii) the estimation of the $\beta$-convergence includes fixed effects, which make the objective of convergence vary per sector, year and company size, these variations not being taken into account in the dispersion indicators; iv) finally, the dispersion indicators built up on the interdecile or interquartile range leave out by definition the productivity of companies on the periphery of our sample's distribution, which are part of the estimation of the $\beta$-convergence. In terms of interpretation, the contrast between the two approaches calls for cautiousness: while the dispersion of productivity levels has increased over the last few years, as the dispersion indicators show, the estimations results, with their numerous limitations, do not allow for this increase to be clearly attributed to a weakening convergence of the productivity levels. 


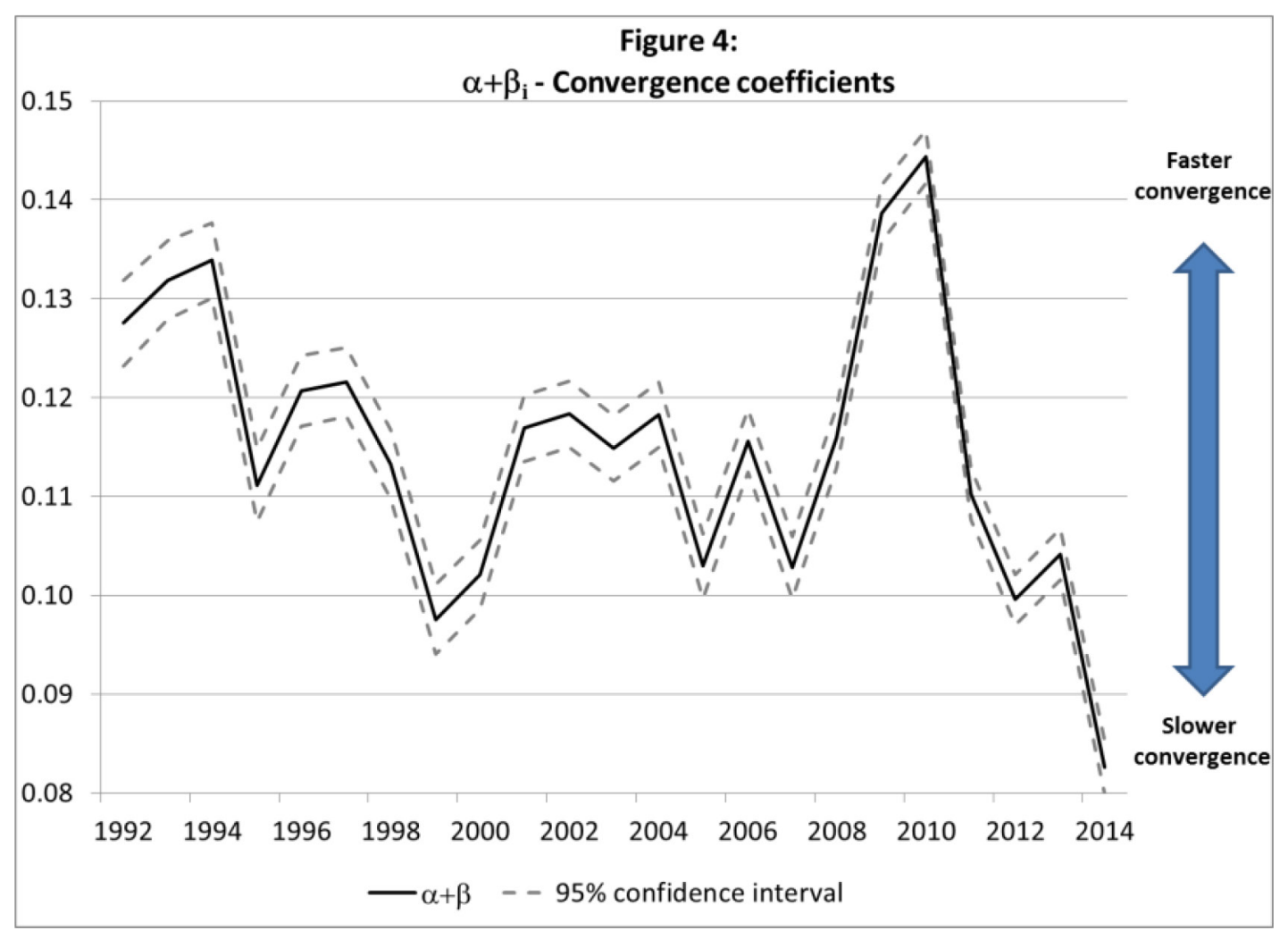

\section{Conclusion}

The main stylised result from this study is an increasing dispersion of firm-level productivity, which points to a deterioration of factor allocation. This may be interpreted as the combination of multiple shocks (technology shocks due to ICT and digitalisation, globalisation, construction slowdown due to the financial crisis...) and a weak reallocation performance, especially on the labour market. Another explanation stems from the decline in real interest rates since the end1980s. This decline allows more and more low-productivity firms to survive and weigh on macroeconomic productivity performance. Such explanation would have a global reach as this decline was observed in all advanced economies.

\section{BIBLIOGRAPHY}

Andrews D., Criscuolo C. \& Gal P. N. (2015). Frontier Firms, Technology Diffusion and Public Policy: Micro Evidence from OECD Countries, OECD Productivity Working Papers 2, OECD Publishing.

Bartelsman, E., Haltiwanger J. \& Scarpetta S. (2013. "Cross-Country Differences in Productivity: The Role of Allocation and Selection," American Economic Review, American Economic Association, vol. 103(1), 305-334, February.

Bergeaud, A., Cette, G. \& Lecat, R. (2016). Productivity trends from 1890 to 2012 in advanced countries. The Review of Income and Wealth, 62(3), 420-444.

Cette, G., Corde, S. \& Lecat, R. (2017). Stagnation de la productivité en France : héritage de la crise ou ralentissement structurel ? Economie et statistique, 494-495-496, 11-38.

Chevalier, P. A., Lecat, R. \& Oulton, N. (2012). Convergence of firm-level productivity, globalisation and information technology: Evidence from France. Economics Letters,116 (2012) 244-246.

Gordon, R. (2012). Is U.S. Economic Growth Over? Faltering Innovation Confronts the Six Headwinds. National Bureau of Economic Research, Inc, NBER Working Papers No 18315. 


\title{
Dispersion et convergence de la productivité des entreprises
}

\begin{abstract}
RÉSUMÉ
Différentes causes possibles du ralentissement de la productivité sont analysées : un affaiblissement des effets du progrès technique, un impact de la révolution digitale ou une allocation des facteurs de production moins efficace. En mobilisant des données individuelles de firmes localisées en France, nous montrons que la productivité a accéléré à la frontière technologique, surtout sur la période récente, ce qui dément l'hypothèse d'un ralentissement des innovations. Cependant, les firmes les plus performantes une année donnée ne semblent pas améliorer ensuite leur position relative. La convergence des niveaux de productivité ne parait pas s'être affaiblie sur les années 2000, ce qui contredit aussi l'hypothèse d'un affaiblissement de la diffusion des innovations des firmes les plus performantes (la frontière technologique) vers les autres. Mais, par ailleurs, la dispersion inter-firmes des niveaux de productivité a augmenté, ce qui suggère un affaiblissement de l'efficacité de l'allocation des facteurs de production, capital et travail, entre les firmes.
\end{abstract}

Mots-clés : productivité globale des facteurs, diffusion de l'innovation la position de la Banque de France. Ils sont disponibles sur publications.banque-france.fr 